\title{
Mercury Accumulation and Distribution in Medaka after the Exposure to Sublethal Levels of Methylmercury
}

\author{
C.-Y. Liao, Q.-F. Zhou, J.-B. Shi, J.-J. Fu, G.-B. Jiang
}

State Key Laboratory of Environmental Chemistry and Ecotoxicology, Research Center for Eco-Environmental Sciences, Chinese Academy of Sciences, Post Office Box 2871, Beijing 100085, People's Republic of China

Received: 26 January 2005/Accepted: 19 July 2005

Mercury is a highly toxic element and studies on its intake, accumulation and transformation have become more numerous (Baatrup, 1991; Chang, 1996; Cai et al., 1997). Among mercury species, methylmercury (MeHg) is the most toxic compound. Investigations of its intake, accumulation, biotransformation, and excretion in fish can help to understand the specific toxic effects on organs/tissues (Heath, 1995). It is estimated that 75-95\% of total mercury (T-Hg) accumulated in fish is in the form of $\mathrm{MeHg}$ (Gochfeld, 2003). Accordingly, the determination of $\mathrm{T}-\mathrm{Hg}$ may indirectly reflect the $\mathrm{MeHg}$ amount accumulated in fish and evaluate its corresponding toxic effects. It is also much of significance to measure the distribution of mercury in various tissues in organisms, which help to find the target organs and understand the toxicological mechanisms of the pollutants.

Japanese medaka fish (Oryzias latipes) is currently used as a kind of useful experimental animal model for the toxicological researches on xenobiotics, due to its superior biological characteristics, such as small body size, short sexual mature age, and easiness to rear. Lots of reports on the toxic effects of endocrine disruptors on medaka have been well documented by the evaluation of its reproduction, development and other symptoms (Islinger et al., 2002; Kang et al., 2002). However, little is known about the intake, accumulation and transformation of $\mathrm{MeHg}$ in medaka fish under sublethal levels of methylmercury chloride (MMC) exposure, resulting in the unclear intoxication mechanisms in medaka (Wester et al., 1991). Herein, after sublethal exposure to a series of MMC polluted solutions for a period of time, total mercury contents in diverse tissues, including liver, brain, gill, gonad, muscle, and fat, from the adult medaka fishes (experiment I) and in the whole fish bodies from the juveniles (experiment II) were measured by using the cold vapor-atomic fluorescence spectrometry (CV-AFS), respectively. Based on results above, the accumulation and distribution of mercury compounds in medaka fish tissues were discussed in detail.

\section{MATERIALS AND METHODS}

A batch of 10-month-old Japanese medaka with the mean value of $3.89 \mathrm{~cm}$ in 
Table 1. Experimental conditions for cold vapor-atomic fluorescence spectrometry.

Hydride generation

$\mathrm{KBH}_{4}$ concentration

$\mathrm{HCl}$ concentration

Sampling time

Hydride generation time

AFS

Lamp

PMT voltage

Primary current

Carrier gas

\author{
$0.2 \%(\mathrm{~m} / \mathrm{v})$ \\ $1.2 \mathrm{~mol} \mathrm{~L}^{-1}$ \\ $2 \mathrm{~s}$ \\ $18 \mathrm{~s}$
}

Hollow cathode lamp, $253.7 \mathrm{~nm}$

$280 \mathrm{~V}$

$40 \mathrm{~mA}$

$\mathrm{N}_{2}, 800 \mathrm{~mL} \min ^{-1}$

length and $0.5763 \mathrm{~g}$ in mass and juvenile medaka of 10 days old $(5.61 \mathrm{~mm}$ in body length; $0.85 \mathrm{mg}$ in mass) were used for adult fish exposure to methylmercury chloride (MMC). The test fish were pre-raised in a flow-through system continuously supplied with the water that was dechlorinated by activated charcoal filters and constantly aerated. The water qualities were controlled as follows: pH 6.9-7.9; oxygen concentration $5-7 \mathrm{mg} / \mathrm{L}$; hardness of $\mathrm{CaCO}_{3} 200$ $\mathrm{mg} / \mathrm{L}$; conductivity $650 \mu \mathrm{S} / \mathrm{cm}$; the water temperature $22.5-25.5^{\circ} \mathrm{C}$. They were fed twice a day with a commercial ration of Artemia and kept under a 12/12h of light/dark cycle. These fish are all healthy and suitable for the routine toxicological exposure experiments.

Mercury was detected by an AF-620 non-dispersive atomic fluorescence spectrometer (Beijing Rayleigh Analytical Instrument Co., China) after hydride generation. The optimized experimental parameters were listed in Table 1.

Appropriate amount of methylmercury chloride (MMC, 98\%, Merck-Schuchardt) was dissolved in methanol to give a stock solution of $1 \mathrm{mg} \mathrm{Hg} / \mathrm{mL}$, which was maintained in a sealed brown volumetric flask at $4^{\circ} \mathrm{C}$. The working solution (1 $\mu \mathrm{g} \mathrm{Hg} / \mathrm{mL}$ ) was prepared by the dilution of the stock solution with de-ionized water just before use. All other reagents used were of analytical pure or better.

Based on the $96 \mathrm{LC}_{50}$ value of $94 \mathrm{ng} \mathrm{Hg} / \mathrm{mL}$ obtained from the acute exposure test, a graded series of sublethal concentrations of MMC $(40,20,10,5,2.5 \mathrm{ng}$ $\mathrm{Hg} / \mathrm{mL}$ and control) were administered to adult medaka fishes by static aquatic solution. After 16-day's exposure to MMC, 20 test fish in the group of $10 \mathrm{ng} / \mathrm{mL}$ were subsequently transferred to clean water for 8-day's elimination experiment. Half of the exposure solution was renewed per day in each treatment. Sampling 1 and 2 at day 8 and day 16 , respectively were the exposure part of the experiment and sampling 3 at day 24 was the elimination part of the experiment. Five fish were collected in each group per sampling. The liver, brain, gill, gonad, muscle, and abdomen fat were collected for the study of $\mathrm{MeHg}$ distribution in various tissues.

The MMC treatment experiment for juvenile medaka was carried out by static 
aquatic solution exposure for 180 days. The MMC concentrations were set as 0,1 , $0.1,0.01 \mathrm{ng} \mathrm{Hg} / \mathrm{mL}$, which were chosen according to the environmental pollution level in some typical mercury polluted rivers of China (Wu et al., 1994). Half of the exposure solution was renewed per day in each treatment. The sampling was set in the $5^{\text {th }}$ and $6^{\text {th }}$ months, which were called sampling $A$ and $B$, respectively. All the samples were immediately kept at $-20^{\circ} \mathrm{C}$ until analysis.

In experiment $\mathrm{I}$, various tissues from five fish per concentration were pooled for mercury content analysis as described previously (Liang et al., 2003). In brief, about 0.1-0.2 g of homogenate tissues were weighed into a PTFE digestion container. Two milliliter of concentrated nitric acid was added and the containers were sealed and left to predigest overnight on an electrothermal hotplate at $60^{\circ} \mathrm{C}$. After cooling, $1 \mathrm{~mL}$ of $\mathrm{H}_{2} \mathrm{O}_{2}(30 \%)$ was added into the containers, which were thereafter placed in stainless steel bombs and sealed with a screw closure to avoid any acid leakage and placed in an oven. The oven temperature was first raised to $50^{\circ} \mathrm{C}$ and kept for $1 \mathrm{~h}$, then increased to $160^{\circ} \mathrm{C}$ for another $6 \mathrm{~h}$. After cooling to room temperature, the solutions were completely transferred into a $50 \mathrm{~mL}$ PET bottle and diluted with Milli-Q water. The digested samples were then determined by cold vapor-atomic fluorescence spectrometry (CV-AFS) method. The method detection limit $(3 \sigma)$ was approximately $0.008 \mathrm{ng} / \mathrm{mL}$. The certified reference material DORM-2 (Dogfish muscle) was analyzed to validate the method and the obtained results $(4715 \pm 302 \mathrm{ng} / \mathrm{g}$, mean $\pm \mathrm{SD}, \mathrm{n}=4$ ) proved to be in good agreement with the certified values $(4640 \pm 260 \mathrm{ng} / \mathrm{g})$, which confirmed the feasibility of the analytical protocols herein in the determination of $\mathrm{T}-\mathrm{Hg}$ in medaka. In experiment II, about 0.1-0.2 g of whole body from a juvenile medaka fish was used for the subsequent analysis. Each sample was analyzed three times for the stability confirmation of the whole procedure. Reagent blanks were processed simultaneously to eliminate the error induced by analytical procedure.

Statistical differences $(P<0.05)$ between the groups were determined by one-way analysis of variance (ANOVA).

\section{RESULTS AND DISCUSSION}

High levels of T-Hg were detected in the exposed fish in experiment $\mathrm{I}$, which ranged from 0.41 to $177.69 \mu \mathrm{g} \mathrm{Hg} / \mathrm{g}$ (wet weight). Figure 1 showed the comparison of T-Hg contents in various tissues from sampling 1 and 2 in experiment I. Clearly, the liver accumulated relatively high levels of T-Hg in most of cases. The highest concentration in the liver, $88.7 \mu \mathrm{g} \mathrm{Hg} / \mathrm{g}$ (w.w.), existed in the group of $40 \mathrm{ng} / \mathrm{mL}$ from sampling 1 , herein. It was explicable that liver, as a major detoxification organ for most organisms, usually has significantly higher levels of pollutants than other tissues. It was also worth noticing that high levels of $\mathrm{Hg}$ existed in brain. This could be explained by the fact that $\mathrm{MeHg}$ could readily penetrate organism's skin and pass the blood-brain barrier, inducing neurological damage in the brain (Baatrup, 1991; Zheng et al., 2003). Under high dose exposure for a certain period, the fish liver accumulated quite high level of 


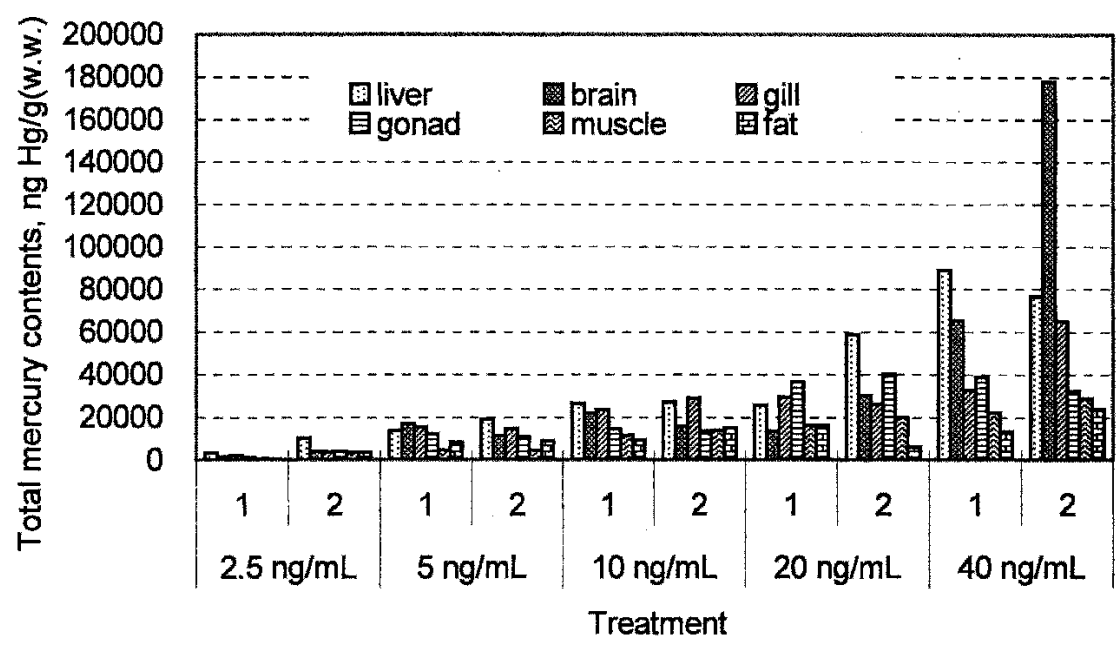

Figure 1. Total mercury contents in medaka tissues from sampling 1 and 2 in experiment $\mathrm{I}_{3}$ ng Hg/g (w.w.). "1": sampling 1; "2": sampling 2.

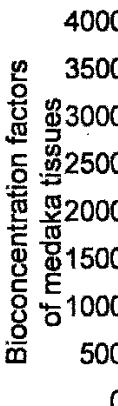

$\begin{array}{lllll}2.5 & 5 & 10 & 20 & 40 \mathrm{ng} / \mathrm{mL}\end{array}$

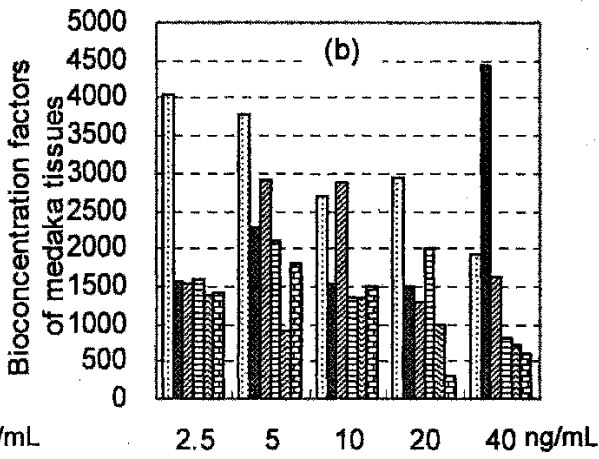

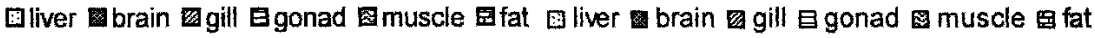

Treatment

Figure 2. Bioconcentration factors of medaka tissues from sampling 1 (a) and 2 (b) in experiment I.

$\mathrm{MeHg}$ and part of the MeHg could readily redistributed to another target organ brain over time (Bäckström, 1969; Ribeyre and Boudou, 1984a), which might explain why the highest level of $177.69 \mu \mathrm{g} \mathrm{Hg} / \mathrm{g}$ (w.w.) was found in the fish brain exposed to $40 \mathrm{ng} / \mathrm{mL}$ for 16 days. The respiratory system provides the most extensive interface of a fish with the aquatic environment. Because of this fact and its delicate epithelium, it is frequently the first system to be affected by pollutants. According to figure 1 , gill tissue was also able to accumulate relatively 
high levels of $\mathrm{Hg}$ compounds. The other two tissues, namely fat and muscle, had similar low abilities for mercury accumulation compared with the other tissues studied. Although it was usually thought that lipophilic pollutants easily accumulate in fat, the results obtained herein showed medaka's fat tissue was not the most important target for MMC exposure. Previous researches found similar results. Vahter et al. (1994) reported that in several female monkeys (Macaca fascicularis) with heavy weight $(5.0-6.1 \mathrm{~kg}$ body wt) exposed to daily peroral doses of $\mathrm{MeHg}$, blood mercury content increased to about $2 \mathrm{~g} \mathrm{Hg} / \mathrm{g}$, indicating limited distribution of $\mathrm{MeHg}$ to fat. In a survey on mercury pollution in alligators (Alligator mississippiensis) from several areas in the southeastern United States, the mercury concentrations in fat collected from Okefenokee were somewhat higher than that in bone, but quite lower than those in other tissues such as liver, kidney, brain, muscle, blood, and spleen (Jagoe et al., 1998). The mechanisms of mercury's distribution and accumulation in various tissues of organisms, such as medaka, are rather complex and need further studies.

High accumulation of mercury compounds in the exposed medaka was found to be dose- and time-dependent in various tissues according to figure 1. Similar results were obtained by Hartman (1978) in rainbow trout exposure test. Zhou et al. (1998) also reported that after sublethal $\mathrm{MeHg}$ exposure, the larval mummichogs (Fundulus heteroclitus) exhibited elevated $\mathrm{Hg}$ levels, which were positively related to exposure concentrations and exposure time. It is well known that fish eliminates methylmercury very slowly compared to its uptake rate (McKim et al., 1976), and the body burden of mercury increases with fish's age or exposure time (Spry and Wiener, 1991). The total body burden of an exogenous chemical would be a weighted mean of all the tissues, which may greatly differ from each other in concentration of the chemical by orders of magnitude (Heath, 1995). Comparatively, as shown in figure 1, liver and brain accumulated more mercury than other tissues, which might indicate that these two tissues should be the sensitive target organs of medaka for monitoring mercury compounds in the environment.

The bioconcentration factor (BCF) is a ratio obtained by dividing the pollutant's concentration in organisms or tissues by the exposure concentration. It can be used to evaluate the bioaccumulation ability of organisms or tissues for the specific chemical. Figure 2 showed the BCFs of medaka tissues in different exposure groups from sampling 1 and 2 in experiment I. Relatively high BCF values in various tissues during short exposure time ( 8 or 16 days), ranging from 165 to 4442 , reflected the powerful bioaccumulation ability of medaka for waterborne MMC. The high mean values of 2538 in liver and 1978 in brain showed the extreme high bioaccumulation abilities for mercury compounds in both organs. Generally, the BCFs of medaka tissues exposed to high concentrations of $\mathrm{MMC}$ were comparatively low. Obvious negative correlation existed between the BCFs and exposure concentrations. For instance, the BCFs of liver from sampling 2 in 5 exposure groups (namely, 2.5, 5, 10, 20, $40 \mathrm{ng} / \mathrm{mL}$ ) were $4028,3759,2696,2929$, and 1908, respectively. Zhou et al. (1998) revealed that for larval mummichogs whose parent fish were collected from a reference 


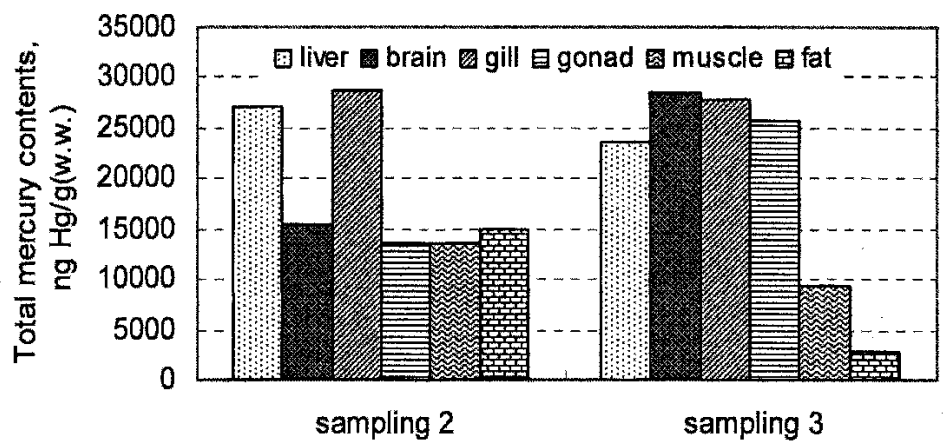

Figure 3. Comparison of total mercury contents in diverse medaka tissues from sampling 2 and 3 in the group exposed to 10 $\mathrm{ng} / \mathrm{mL}$ of methylmercury chloride in experiment $\mathrm{I}, \mathrm{ng} \mathrm{Hg} / \mathrm{g}$ (w.w.)

site (Tuckerton in New Jersey) without heavy metal pollution, the BCFs were not related to the exposure concentration but relevant to exposure time and larval age, indicating that the larvae could modulate the relative $\mathrm{Hg}$ uptake and excretion to a certain extent. Considering the absolute value, $\mathrm{T}-\mathrm{Hg}$ contents in medaka tissues at higher exposure levels were overtly higher than those at lower exposure levels. This negative correlation between $\mathrm{BCF}$ and exposure concentrations might be interpreted by the fact that high levels of MMC exposure led to the fish accumulating mercury compounds close to their threshold values after a period of time. Through observation of mercury accumulation in Salmo gairdneri, Ribeyre and Boudou (1984a) reported that the mercury bioaccumulation apparently showed as sigmoid curves (fish organs showing a saturated accumulation curve) and the high concentrations corresponded to slow accumulation rates. The accumulation rate would gradually reduce although the absolute accumulation amount still increased. It was accordingly reasonable that BCFs were negatively related with the exposure levels. Figure 2 also showed that in most cases, the BCFs slightly increased with prolong of exposure time. This was mainly due to the mercury contents accumulated in the exposed tissues increased with the exposure time, which was consistent with mercury accumulation trend described above.

Studies on elimination of mercury in the organisms might offer some information on detoxification process. An 8-day elimination experiment was conducted using twenty exposed fish from the group of $10 \mathrm{ng} \mathrm{Hg} / \mathrm{mL}$. Figure 3 showed the comparison of T-Hg contents in the samples from sampling 2 and 3 . The data showed that there were no significant differences in the mercury contents for diverse tissues between two samplings $(P<0.05)$. The results indicated that once $\mathrm{MeHg}$ accumulated in medaka fish, its excretion was very difficult and slow, which confirms studies by other researchers (McKim et al., 1976; Pentreath, 1976; Ribeyre and Boudou, 1984b). Additionally, T-Hg contents in some tissues like brain and gonad from sampling 3 were higher than those from sampling 2, which meant the reallocation of mercury compounds in the fish bodies. The phenomena 
Table 2. Total mercury contents in the whole bodies of juvenile medaka from two times' samplings in experiment II, $\mu \mathrm{g} \mathrm{Hg} / \mathrm{g}$ (w.w.).

\begin{tabular}{lllll}
\hline & \multicolumn{2}{c}{ Sampling A } & \multicolumn{2}{c}{ Sampling B } \\
\cline { 2 - 5 } & Concentration & BCF & Concentration & BCF \\
\hline $0.01 \mathrm{ng} / \mathrm{mL}$ & $0.055 \pm 0.029^{\mathrm{a}}$ & 5543 & $0.043 \pm 0.008$ & 4275 \\
$0.1 \mathrm{ng} / \mathrm{mL}$ & $0.485 \pm 0.045$ & 4846 & $0.484 \pm 0.034$ & 4842 \\
$1 \mathrm{ng} / \mathrm{mL}$ & $3.344 \pm 0.357$ & 3344 & $3.336 \pm 0.127$ & 3336 \\
\hline
\end{tabular}

mean \pm S.D., $n=3$

might also reveal that brain and gonad were the definite target organs of mercury compounds.

Juvenile organisms were usually more sensitive to the pollutants than the adults, which enable them to be widely used in the toxicological researches. Mercury accumulation was also studied herein using juvenile medaka as the experimental animal to confirm its feasibility in the experiments. Table 2 listed T-Hg contents in the bodies of juvenile medaka from two samplings in experiment II. It could be seen that the bioaccumulation abilities of mercury in these juveniles were also very strong. Comparatively high BCFs, ranging from 3336 to 5543, of the bodies of juveniles in experiment II were also listed in Table 2 . Similar to the experiment $I$, a dose-dependent increase of mercury contents and a negative correlation relationship between $\mathrm{BCF}$ s and exposure concentrations were also observed here. Exposure time didn't have obvious effect on mercury contents in juveniles, which might be explained by the fact that 5-6 months were long enough for the test fish achieve mercury metabolism balance in their bodies. All the results obtained above suggested that juvenile medaka could accumulate trace levels of mercury compounds, which might enable them to be the useful tools for the monitoring of environmental organometallic pollution and toxicological studies.

Acknowledgments. This work was jointly supported by the Chinese Academy of Sciences (KJCX2-SW-H06) and the National Basic Research Program of China (2003CB415001).

\section{REFERENCES}

Baatrup E (1991) Structural and functional effects of heavy metals on the nervous system, including sense organs, of fish. Comp Biochem Physiol C 100: 253-257

Bäckström J (1969) Distribution studies of mercuric pesticides in quail and some freshwater fishes. Acta Pharmacol Toxicol 27: 3-103

Cai Y, Tang G, Jaffé R, \& Jones R (1997) Evaluation of some isolation methods for organomercury determination in soil and fish samples by capillary gas chromatography-atomic fluorescence spectrometry. Intern J Environ Anal Chem 68: 331-345

Chang LW (1996) Toxico-neurology and neuropathology induced by metals. In: Chang LW editor. Toxicology of metals. Boca Raton (FL): CRC Lewis Publisher, p 511-535 
Gochfeld M (2003) Cases of mercury exposure, bioavailability, and absorption. Ecotox Environ Safe 56: 174-179

Hartman AM (1978) Mercury feeding schedules: effects on accumulation, retention and behavior in trout. Trans American Fish Soc 107: 369-375

Heath AG (1995) Uptake, accumulation, biotransformation, and excretion of xenobiotics. In: Heath AG editor. Water pollution and fish physiology. Boca Raton (FL): CRC Lewis Publisher, p 79-123

Islinger M, Yuan H, Voelkl A, Braunbeck T (2002) Measurement of vitellogenin gene expression by RT-PCR as a tool to identify endocrine disruption in Japanese medaka (Oryzias latipes). Biomarkers 7: 80-93

Jagoe $\mathrm{CH}$, Arnold-Hill B, Yanochko GM, Winger PV, Brisbin Jr IL (1998) Mercury in alligators Alligator mississippiensis in the southeastern United States. Sci Total Environ 213: 255-262

Kang IJ, Yokota H, Oshima Y, Tsuruda Y, Yamaguchi T, Maeda M, Imada N, Tadokoro H, Honjo $\mathrm{T}$ (2002) Effects of 17beta-estradiol on the reproduction of Japanese medaka (Oryzias latipes). Chemosphere 47:71-80

Liang LN, Shi JB, He B, Jiang GB, Yuan CG (2003) Investigation of Methylmercury and Total Mercury Contamination in Mollusks Samples Collected from Coastal Sites along the Chinese Bohai Sea. J Agr Food Chem 51: 7373-7378

McKim J, Olson G, Holcombe G, Hunt $E$ (1976) Long-term effects of methylmercuric chloride on three generations of brook trout (Salvelinus fontinalis): toxicity, accumulation, distribution and elimination. J Fish Res Bd Canada 33: 2726

Pentreath RJ (1976) The accumulation of mercury from food by the plaice, Pleuronectes platessa L. J Exp Mar Biol Ecol 25:51-65

Ribeyre $\mathrm{F}$ and Boudou $\mathrm{A}$ (1984a) Bioaccumulation et repartition tissuelaire du mercure- $\mathrm{HgCl}_{2}$ et $\mathrm{CH}_{3} \mathrm{HgCl}$-chez Salmo gairdneri, après contamination par voie directe. Water Air Soil Poll 23: 169-186

Ribeyre F and Boudou A (1984b) Etude expérimentale des processus de décontamination chez Salmo gairdneri, après contamination par voie directe deux dérivés du mercure $\left(\mathrm{HgCl}_{2}\right.$ et $\mathrm{CH}_{3} \mathrm{HgCl}$ )-analyse des transfert aux niveaux 'organisme' et 'organes'. Environ Pollut 35: 203-228

Spry D and Wiener J (1991) Metal bioavailability and toxicity to fish in low alkalinity lakes: a critical review. Environ Pollut 71: 243

Vahter M, Mottet NK, Friberg L, Lind B, Shen DD, Burbacher T (1994) Speciation of Mercury in the Primate Blood and Brain Following Long-Term Exposure to Methyl Mercury. Toxicol Appl Pharmacol 124: 221-229

Wester PW, Canton JH (1991) The usefulness of histopathology in aquatic toxicity studies. Comp Biochem Physiol C 100: 115-117

Wu SA, Zhang GL, Xu J, Wang XZ (1994) Environmental epidemiological study on the chronic methylmercury poisoning along the SongHua River. Chin Environ Sci 14: 268-272

Zheng W, Aschner M, Ghersi-Egea JF (2003) Brain barrier systems: a new frontier in metal neurotoxicological research. Toxicol Appl Pharm 192: 1-11

Zhou T, Weis P, Weis JS (1998) Mercury burden in two populations of Fundulus heteroclitus after sublethal methylmercury exposure. Aquat Toxicol 42: 37-47 